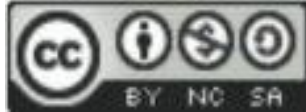

\title{
EL HABEAS DATA EN EL CONTEXTO DE LOS DERECHOS DIGITALES Y LOS "VULNERABLES" TECNOLÓGICOS. UNA TUTELA PROCESAL DIFERENCIADA
}

O HABEAS DATA NO CONTEXTO DOS DIREITOS HUMANOS DIGITAIS E DOS "VULNERÁVEIS" TECNOLÓGICOS. UMA TUTELA PROCESSUAL DIFERENCIADA.

HABEAS DATA FROM THE CONTEXT OF DIGITAL HUMAN RIGHTS AND TECHNOLOGICAL "VULNERABLE" PEOPLE. A DIFFERENTIATED PROCEDURAL GUARDIANSHIP.

Ignacio M. Soba Bracesco Doctor en Derecho y Ciencias Sociales de la Facultad de Derecho de la Universidad de la República Oriental del Uruguay. Magíster en Derecho (Facultad de Derecho, Universidad de la República.

\begin{abstract}
Resumo
As pretensões vinculadas à temática do habeas data próprio (proteção de dados pessoais) e impróprio (acesso à informação pública) exigem ferramentas processuais idôneas e efetivas para seu devido julgamento. A consagração de tutelas processuais diferenciadas no Direito Processual uruguaio (Leis no 18.331 e 18.381 e suas alterações) é um exemplo disso. Ali se estabelece um processo do tipo sumário, especial e autônomo para a apreciação de pretensões referentes ao habeas data próprio e impróprio. Trata-se, em definitivo, de refletir acerca da efetividade dos direitos digitais das pessoais, em um contexto no qual nos encontramos ante uma multiplicidade de sujeitos vulneráveis, do ponto de vista tecnológico.
\end{abstract}

Palavras-chave: habeas data, dados pessoais, informação pública, tutela diferenciada.

Abstract
The claims related to the theme of habeas own data (protection of per-
sonal data) and improper (access to public information) require appro-
priate and effective procedural tools for its substantiation. The conse-
cration of differentiated procedural guardianships in Uruguayan proce-
dural law (Laws No. 18,331 and 18,381 and amendments) is an exam- 
ple of this. In summary, a special and autonomous process is established for the substantiation of claims related to habeas own and improper data. It is to reflect on the effectiveness of the digital rights of people, in a context in which we face a multitude of vulnerable subjects from the technological point of view.

Keywords: habeas data, personal data, public information, special guardianship.

SUMARIO: I) Introducción. II) El habeas data y sus circunstancias. Por una justicia de rostro más humano y simple. III) El habeas data en Uruguay (o el extraño caso de un amparo que no es un amparo). i) Presupuestos o requisitos previos del proceso judicial. ii) La demanda, emplazamiento y audiencia. iii) Sentencia, cosa juzgada y ejecución. IV) A modo de cierre. Los "vulnerables" tecnológicos]

\section{I) INTRODUCCIÓN}

Resulta una obviedad destacar, hoy en día, la importancia de la protección de datos personales (habeas data en sentido propio) o del acceso a la información pública (habeas data en sentido impropio). Tanto que se podría hablar de una nueva generación de derechos: los derechos digitales de las personas. ${ }^{1}$

La concentración de información, el manejo masivo, automatizado, opaco e indiscriminado de datos, conforman reductos incuestionables de poder. ${ }^{2}$

De modo subyacente a esa realidad, se pueden encontrar, cotidianamente, vulneraciones a diversos derechos fundamentales.

En el caso de los datos personales, y aunque muchos parezcan olvidarlo o desconocerlo, están en juego cuestiones tan elementales y fundamentales como la protección de la dignidad, la intimidad y la privacidad (ultra perforada y violentada, pero también pasible de ser tutelada), el honor, etc. $\mathrm{O}$, con una visión más actual, y entre

\footnotetext{
${ }^{1}$ En ese sentido, véase Exposición de Motivos de la Ley Orgánica 3/2018, de 5 de diciembre, de Protección de Datos Personales y garantía de los derechos digitales, en BOLETíN OFICIAL DEL ESTADO [España]: < https://www.boe.es/buscar/act.php?id=BOE-A-2018-16673> (consultado el 09/10/2019).

${ }^{2}$ Como señalan Pinto Palacios y Pujol Capilla: “...la monitorización constante de nuestra actividad en la red a través de las llamadas cookies ofrece una información muy valiosa a la hora de determinar los hábitos de consumo de una persona. Esta información tiene un considerable valor comercial (...). Por esta razón, han surgido empresas que se dedican a analizar los big data procedentes de los historiales de navegación de millones de usuarios con la finalidad de desarrollar estrategias comerciales más efectivas dado su alto grado de especialización.". Cfr., PINTO PALACIOS, F., PUJOL CAPILLA, P., La prueba en la era digital, La Ley - Wolters Kluwer, Madrid, 2017, p. 21.
} 
otros, el llamado derecho al olvido o el "derecho a la no indexación" por parte de buscadores como Google. ${ }^{3}$

El acceso al dato personal -y el control sobre el mismo- se ha impuesto como una necesidad al verse los individuos enfrentados al absurdo de no tener información sobre los datos que existen sobre sí mismos. El cúmulo de información generado por las personas es tan vasto que puede volverse hasta desconocido para el propio titular del dato. ${ }^{4}$

En los supuestos de acceso a la información pública, mientras tanto, muchos valores de relevancia democrática y, eventualmente, republicana, como la transparencia y el conocimiento de la información en poder de los organismos públicos, se transforman en condición necesaria para el ejercicio de derechos y libertades fundamentales. No basta, por cierto, con las políticas de transparencia activa (a través de las cuales los propios organismos publican información, utilizando fundamentalmente para ello plataformas digitales), sino que se necesita contar con vías adecuadas de acceso por parte de las personas.

Tal como lo ha reconocido la Suprema Corte de Justicia en Uruguay, citando lo expuesto en doctrina y en la jurisprudencia de la Corte Interamericana de Derechos Humanos (caso "Claude Reyes y Otros vs. Chile", sentencia de 19 de septiembre de 2006, Fondo, Reparaciones y Costas), en una sociedad democrática es indispensable que las autoridades estatales se rijan por el principio de máxima divulgación, el cual establece la presunción de que toda información es accesible, sujeto a un sistema restringido de excepciones. ${ }^{5}$

Las herramientas para la protección de los datos personales, así como para el acceso a la información pública, se vuelven, pues, garantías indispensables en el marco del bloque de derechos humanos y/o fundamentales. Es por ello que resulta inconcebible adoptar una actitud prescindente respecto de una cuestión tan trascendente y cada vez más compleja.

El presente trabajo se abocará, principalmente, a la reflexión en torno a la consagración de tutelas procesales diferenciadas, como garantía de justiciabilidad de los

\footnotetext{
${ }^{3}$ BUENO DE MATA, F., Prueba electrónica y proceso 2.0., Tirant lo Blanch, Valencia, 2014, pp. 157-161. ${ }^{4}$ Sobre la historia y explicación del habeas data, GAIERO GUADAGNA, B. J., SOBA BRACESCO, I.M., La regulación procesal del habeas data, BdeF, Buenos Aires, 2010, pp. 1-23.

${ }^{5}$ Suprema Corte de Justicia, sentencia n 802/2018, de 04/06/2018 (Minvielle -redactor-, Martínez, Chediak, Hounie, Turell).
} 
denominados habeas data propio (o protección de datos personales) y habeas data impropio (o acceso a la información pública).

En ese sentido, se estudiará algunas regulaciones del Derecho comparado, así como el caso de la legislación uruguaya, a más de diez años de la aprobación de leyes № 18.331 y № $18.381 .{ }^{6}$

En definitiva, y sirviendo dichas leyes como muestra, el análisis de los aspectos procesales y de garantías involucrados en el habeas data, resulta necesario a efectos de fomentar un mayor desarrollo de la cultura jurídica vinculada al ejercicio de los derechos fundamentales.

\section{II) EL HABEAS DATA Y SUS CIRCUNSTANCIAS. POR UNA JUSTICIA DE ROSTRO MÁS HUMANO Y SIMPLE}

El contexto actual es de desafíos, avance precipitado e inusitado de la tecnología, de acumulación de información en todos los ámbitos, sean privados o públicos. Y, al mismo tiempo, de personas que parece que se tienen que enfrentar a lo imposible, cuando lo que buscan es una respuesta rápida, soluciones sencillas y tutela efectiva a sus problemas de la vida.

Tal como se manifiesta en el considerando $n^{\circ}$ 9) del Reglamento de la Unión Europea 2016/679, del Parlamento Europeo y del Consejo, de 27 de abril de 2016, "relativo a la protección de las personas físicas en lo que respecta al tratamiento de datos personales y a la libre circulación de estos datos y por el que se deroga la Directiva 95/46/CE (Reglamento general de protección de datos)", existe "una percepción generalizada entre la opinión pública de que existen riesgos importantes para la protección de las personas físicas, en particular en relación con las actividades en línea.".

Ese es el contexto que tiene que afrontar la normativa actual. Según observa Barrios De Ángelis: "El medio histórico en que cada norma se desenvuelve es un conglomerado de fenómenos materiales y espirituales; de institutos, preconceptos, técnicas de todo carácter, cultura o culturas interpenetradas...". ${ }^{7}$ Sobre algo similar ilustraba Couture cuando expresaba que: "La redacción de un Código no es una obra

\footnotetext{
${ }^{6}$ Ley $\mathrm{N}^{\circ} 18.331$, promulgada el 11 de agosto de 2008 y publicada en el diario oficial el 18 de agosto de 2008 (protección de datos personales o habeas data propio) y Ley $N^{\circ} 18.381$, promulgada el 17 de octubre de 2008 y publicada en el diario oficial el 7 de noviembre de 2008 (acceso a la información pública o habeas data impropio). Se puede acceder al texto actualizado de dichas leyes a través de la base de datos normativa del sitio web del Diario Oficial en Uruguay: <https://www.impo.com.uy/bases/leyes/18331-2008> <https://www.impo.com.uy/bases/leyes/18381-2008> (consultados el 09/10/2019).

${ }^{7}$ Cfr., BARRIOS DE ÁNGELIS, D., El proceso civil, Idea, Montevideo, 1989, p. 28.
} 
académica sino una obra política. No tiene por finalidad consagrar principios de cátedra, sino solucionar los problemas que la realidad social, económica, cultural y ética presenta al legislador.". 8

En efecto, considero que el énfasis se debe poner en las personas, y en buscar soluciones a sus problemas. La tecnología ofrece posibilidades, genera problemas, tiene ventajas, así como desventajas, pero son las personas las que necesitan de tutela.

Precisamente, "Por una justicia de rostro más humano" fue el lema del 1er. Congreso Internacional de Derecho Procesal Civil realizado en Gantes (Bélgica) en 1977. En la convocatoria a dicho Congreso se señalaba: "En una sociedad cada vez más compleja, el derecho procesal debe poder funcionar de una manera más accesible, humana, rápida y eficaz, para que todo ciudadano pueda hacer valer sus derechos. En todo el mundo se están haciendo últimamente esfuerzos para consagrar ese objetivo".

Es por ello que sostengo que la tutela procesal debe ser diferenciada y simple, aunque se trate de una temática compleja.

No se trata de un objeto del proceso que sea simple per se, sino de un objeto que puede ser simplificado en función de una decisión de política legislativa protectora (tal como ha sucedido en el Derecho comparado, cuando se le reconocen ciertas particularidades procesales ya sea a nivel constitucional o legal).

Estos casos se caracterizan por la necesidad de hacer prontamente una cosa, en función de la urgencia derivada del objeto del proceso. ${ }^{9}$

No son simples las cuestiones que se sustancian en las estructuras de habeas data (en sentido amplio), al contrario, son muchas veces muy complejas, sin embargo, se ha decidido simplificarlas, a mi criterio con acierto, por opción de diseño del sistema procesal.

El objeto de estos procesos condiciona la tutela procesal que se debe diseñar institucionalmente para dar respuesta a los problemas de las personas, respetando a su vez el debido proceso.

${ }^{8}$ Cfr., COUTURE, E.J., Proyecto de Código de Procedimiento Civil, Montevideo, 1945, p. 31.

${ }^{9}$ Barrios De Ángelis analiza en su teoría estos objetos implicados por la urgencia, la cual "es definida como la necesidad de hacer prontamente una cosa; en el plano conceptual del objeto, radica en la necesidad de cambio y consiste en la nota de inmediatez, es decir, necesidad de cambio inmediato" (cfr., BARRIOS DE ÁNGELIS, D., Teoría del proceso, BdeF, Montevideo, 2005, p. 252). Según el autor, dicha urgencia en el objeto, en función de lo que él llama ley genética, determina las restantes categorías del proceso. 
Claro que luego podríamos preguntarnos, y con toda lógica, cuál es el grado de simplificación que se debe plasmar en la regulación de los procesos de habeas data, y también si esa simplificación de la estructura no se debería extender a la tramitación de otras pretensiones (en particular, otras pretensiones relacionadas con la tutela, protección o amparo de derechos fundamentales).

Con una visión macro del sistema procesal, cabe dudar de la conveniencia de que proliferen tutelas procesales diferenciadas, procurando cierta unificación de las mismas, apostando a la racionalidad sistémica de todos aquellos casos que no soportan la tramitación del proceso ordinario (el cual, de admitirse casi que al infinito la tutela diferenciada, tendería casi que a desaparecer o a ser muy residual).

Tema aparte, para dejar planteado y seguir reflexionando, es el de si las tutelas diferenciadas, caracterizadas por la sumariedad en la estructura, admiten o no la revisión de lo resuelto en un proceso posterior de tipo ordinario o de mayor estructura, que ofrezca -supuestamente- mayores oportunidades de debate. ${ }^{10}$

En ese sentido, habrá que estar, por un lado, al estándar de prueba que se exija para adoptar la decisión jurisdiccional en el caso del habeas data (id est, ¿es un proceso en el cual la decisión jurisdiccional se puede adoptar en base a la probabilidad preponderante, a la certeza procesal, etc.?); y por otro lado, a lo dispuesto por cada ordenamiento jurídico en materia de impugnaciones, cosa juzgada y/o de eventual revisión de la misma. ${ }^{11}$

Desde ya señalo que, en mi opinión, no hay una relación de necesidad entre mayor estructura procesal y mayores garantías, por lo que no resulta imprescindible prever un proceso posterior de mayores garantías para revisar lo resuelto a través de

\footnotetext{
${ }^{10}$ Según Barrios De Ángelis: “(...) el juicio ordinario es una manifestación de la justicia conmutativa, en cuanto revela que ningún objeto, ninguna causa, puede ser inferior a otra, a priori, en su vocación para ser sometida al máximo de garantías, concepto funcional, que representa el máximo de estructura, concepto estructural.". BARRIOS DE ÁNGELIS, D., Teoría del proceso, BdeF, Montevideo, 2005, p. 250.

${ }^{11}$ Algo similar, aunque no idéntico, acontece con la discusión acerca de la revisión de lo resuelto de modo anticipado en un proceso. A modo de ejemplo, en el art. 5 del Código Modelo de Procesos Colectivos para Iberoamérica (año 2004), del Instituto Iberoamericano de Derecho Procesal, se dispone: "Par. 3o . La tutela anticipada podrá ser revocada o modificada en cualquier tiempo, en decisión fundada. Par. 4o. Si no hubiere controversia en cuanto a la parte anticipada en la decisión liminar, después de la oportunidad de contradictorio ésta se tornará definitiva y hará cosa juzgada, y proseguirá el proceso, si fuere el caso, para el juzgamiento de los demás puntos o cuestiones comprendidas en la demanda.". También en la primera parte del art. 58 del Código Modelo de Procesos Administrativos -Judicial y Extrajudicial- para Iberoamérica (año 2012), del Instituto Iberoamericano de Derecho Procesal se prevé: "1. La tutela de urgencia puede ser conservativa o satisfactiva, correspondiendo, la primera a las medidas cautelares y la segunda a la anticipación de la tutela. El principio de la tutela efectiva comprende la aplicación de las medidas cautelares y anticipativas previstas en el presente capítulo, a efectos de la protección de los derechos subjetivos e intereses legítimos...".
} 
una tutela diferenciada (en el caso, en materia de habeas data). Lo anterior en base a que no existe una única estructura ordinaria (fácilmente de constatar a través de la compulsa del Derecho comparado, e incluso dentro de un mismo ordenamiento procesal), y en mérito a que no se pueden descuidar otras garantías que pueden ser igualmente valiosas, como las que se derivan de la duración razonable que se le exige en cada caso a los procesos jurisdiccionales.

En el caso uruguayo, una de las diferencias más importantes que tienen los procesos de habeas data propio e impropio respecto del proceso de amparo de libertades y derechos consagrados expresa o implícitamente en la Constitución de la República (Ley $N^{\circ} 16.011$, de 19 de diciembre de 1988) es que la sentencia pasa en autoridad de cosa juzgada, formal y material. En el amparo, en cambio, el art. 11 de la citada Ley $\mathrm{N}^{\circ} 16.011$ prevé que la sentencia ejecutoriada hace cosa juzgada sobre su objeto, pero deja subsistente el ejercicio de las acciones que pudieren corresponder a cualquiera de las partes con independencia del amparo.

Finalmente, no se deben dejar de tener presente las enseñanzas de Taruffo sobre la racionalidad y crisis de la ley procesal: "El concepto de racionalidad puede relacionarse con la ley procesal en, al menos, dos sentidos principales: racionalidad como coherencia de la ley procesal y racionalidad como funcionalidad (o racionalidad instrumental) de la misma ley. La coherencia de la ley procesal es una característica que se puede apreciar si imaginamos que se ponen todas las normas procesales de un ordenamiento en un mismo plano, como para componer un mosaico, y se verifica si las distintas partes de éste -sea a nivel de microanálisis, sea a nivel de cada una de las particulares partes del mosaico- son recíprocamente coherentes. Desde esta perspectiva se pueden apreciar algunas propiedades que puede presentar la ley procesal, y se puede -hipotéticamente- establecer también en qué grado estas propiedades están presentes en un sistema procesal dado. Estas propiedades son el orden, o sea, la secuencia en la cual vienen reguladas las actividades procesales (pero también las relaciones entre normas generales y disposiciones específicas); la unidad, que deriva de tratarse de normas que forman un contexto único con un núcleo de normas fundamentales y, posiblemente, pocas normas especiales (p. ej.: un código procesal con pocas leyes o normas procedimentales situadas fuera de él); la plenitud, que se produce cuando la ley procesal regula todos los aspectos relevantes de los mecanismos procedimentales de modo suficientemente analítico, dejando lo menos posible a la fantasía de los intérpretes; y la simplicidad, que existe cuando la ley 
regula de modo claro un procedimiento que se resuelve en un mecanismo relativamente no complejo. Quizás estas propiedades no agotan el concepto de racionalidad como coherencia de la ley procesal, pero tal vez puede decirse que una ley procesal que sea ordenada, unitaria, completa y simple en un nivel apreciable, es racional en una sensata acepción del término." 12 (Énfasis agregado).

En conclusión, desde la perspectiva del diseño racional del sistema procesal, de la instrumentalidad del Derecho procesal y de la tutela jurisdiccional efectiva, se puede señalar que se comparte la necesidad de reconocer una tutela diferenciada que atienda a la urgencia y particularidades de las pretensiones de habeas data, al mismo tiempo que se consagran oportunidades adecuadas para el ejercicio del derecho de defensa y para la realización del debate probatorio.

Asimismo, en función de las especificidades de cada ordenamiento, fundamentalmente en materia de cosa juzgada, habrá que analizar si se admite o no la revisión de lo resuelto en las tutelas sumarias, diferenciadas y/o urgentes de habeas data.

\section{III) EL HABEAS DATA EN URUGUAY (O EL EXTRAÑO CASO DE UN AMPARO QUE NO ES UN AMPARO)}

Dentro de la estructura procesal prevista por las Leyes $\mathrm{N}^{\circ} 18.331$ y 18.381 ( $\mathrm{y}$ modificativas) se puede apreciar una serie de variadas pretensiones vinculadas con el habeas data propio (regulado por la primera de las leyes mencionadas) y aquellas otras referentes al habeas data impropio (regulado por la segunda).

En el caso del habeas data propio, y como lo hemos sostenido con anterioridad, es posible incluso prohibir hacia el futuro el tratamiento de ciertos datos personales, junto con la supresión o eliminación de los que pudieran llegar a existir en un momento determinado. ${ }^{13}$ Se comparte, en ese sentido, lo expresado por Almeida, en cuanto a que es posible por esa vía tutelar el llamado derecho al olvido, obteniendo una sentencia de condena a futuro. ${ }^{14}$

12 TARUFFO M., "Racionalidad y crisis de la ley procesal", en Doxa. Cuadernos de Filosofía del Derecho, № 22, 1999, <http://www.cervantesvirtual.com/obra/racionalidad-y-crisis-de-la-ley-procesal/ > (consultado el 09/10/2019), pp. 311-312.

${ }^{13}$ GAIERO GUADAGNA, B. J., SOBA BRACESCO, I. M., La regulación procesal del habeas data, BdeF, Buenos Aires, 2010, pp. 125-127.

${ }^{14}$ ALMEIDA IDIARTE, R., "La tutela procesal del derecho al olvido", en Revista Uruguaya de Derecho Procesal, 2/2017, FCU, Montevideo, p. 227. 
La jurisprudencia uruguaya ha dado cuenta de la referida amplitud, por ejemplo, en un caso en el que se admitió una demanda de habeas data propio, de tipo asegurativo, con la finalidad justamente de asegurar que los datos no sean comunicados a terceros constituyendo una garantía para la reserva de los mismos (los datos cuya exhibición a terceros se quería evitar versaban sobre transacciones comerciales sobre ciertos cultivos de maíz transgénicos). ${ }^{15}$ Asumiendo una postura más restrictiva en cuanto al objeto del habeas data propio, se rechazó que por la estructura especial del habeas data se pudiera obtener la supresión o declaración de ilegalidad de todo un Registro de datos (el caso refería a un registro de videovigilancia creado por la asamblea de copropietarios en un edificio). ${ }^{16}$

Sin perjuicio de lo anterior (id est, cierta amplitud del objeto de dichos procesos), no se ha admitido a texto expreso que a través de las referidas estructuras especiales se pueda reclamar daños y perjuicios derivados de la afectación de los derechos fundamentales que esas mismas leyes pretenden tutelar. Para la reparación o resarcimiento de dichos daños, las personas deben tramitar un proceso de estructura ordinaria.

La estructura seleccionada por el legislador uruguayo es casi una copia de la prevista para el proceso de amparo de derechos y libertades fundamentales (Ley $\mathrm{N}^{\circ}$ 16.011). Se enmarca en la tendencia legislativa a nivel nacional de otorgarle a la tramitación y sustanciación de ciertas pretensiones una estructura muy similar a la del amparo (ello acontece también en los casos de pretensiones vinculadas a la tutela de la libertad sindical y de casos vinculados al acoso sexual).

La estructura prevista en las leyes de habeas data es sumaria. Junto a Gaiero Guadagna, he entendido que se trata de un proceso sumario en la estructura, pero de cognición plena. No es sumario en cuanto al conocimiento porque lo decidido pasa en autoridad de cosa juzgada tanto formal como material. O sea, implica la composición definitiva y total del litigio o el conflicto en materia de habeas data. ${ }^{17}$

\section{i) PRESUPUESTOS O REQUISITOS PREVIOS DEL PROCESO JUDICIAL}

\footnotetext{
${ }^{15}$ Cfr., Tribunal de Apelaciones en lo Civil de $4^{\circ}$ Turno, sentencia $n^{\circ}$ 273/2010, de 22/11/2010 (Maggi redactor-, Turell, Tobía).

${ }^{16}$ Tribunal de Apelaciones en lo Civil de $3^{\circ}$ Turno, sentencia $n^{\circ}$ 25/2014, de 25/02/2014 (Cardinal -redactor).

${ }^{17}$ GAIERO GUADAGNA, B. J., SOBA BRACESCO, I.M., La regulación procesal del habeas data, BdeF, Montevideo, 2008, pp. 135-142.
} 
A nivel de la regulación legal y reglamentaria uruguaya, se ha optado por exigir con carácter pre-judicial, el cumplimiento de una etapa previa al proceso.

O sea, cumplir con solicitar a quien sería el futuro demandado en el proceso de protección de datos personales, que haga lugar a lo que se le peticiona; o en el caso del acceso a la información pública, el cumplimiento de un procedimiento administrativo especial ante el organismo o la administración pública correspondiente. Estos procedimientos lo que buscan es evitar o precaver algunos de los procesos, permitiéndole acordar o cumplir con las exigencias del solicitante, sin necesidad de llegar a una instancia jurisdiccional.

Se trata de un requisito procesal en sentido amplio, o más bien, de un presupuesto especial. ${ }^{18}$ Su ausencia no implicará, en ningún caso, la nulidad del o los actos procesales realizados, pero advertida su omisión se deberá suspender la tramitación del proceso hasta tanto se verifique su cumplimiento.

En el caso de la protección de datos personales, la normativa uruguaya requiere que se haya cumplido con ciertos requisitos específicos para que quede expedito el proceso judicial. Básicamente, ejercer el derecho de acceso o de rectificación, actualización, inclusión o supresión, directamente ante el responsable de la base de datos pública o privada (también denominado en otros ordenamientos como "el fichero"), el responsable de su tratamiento, o eventualmente otros sujetos que se considere que tienen incidencia en la cuestión y que pueden llegar a tener legitimación, a tales efectos, en el posterior proceso de habeas data. La respuesta o el informe a quien realiza la gestión se debe de otorgar en el breve plazo de cinco días hábiles de solicitada (arts. 14 y 15 de la Ley 18.331 y modificativas, entre otros).

En esa línea la jurisprudencia uruguaya ha expresado que: "La formulación de petición ante el responsable público o privado de la base de datos, y su denegatoria expresa, tácita o por razones que el interesado juzgue no amparadas por la ley, constituye precisamente una cuestión previa, sin la cual carece de legitimación para acudir a la vía jurisdiccional.". ${ }^{19}$

Por su parte, en el caso del proceso de acceso a la información pública, se requiere de la tramitación previa o pre-judicial de un procedimiento de naturaleza administrativa especial para acceder a la información.

\footnotetext{
${ }^{18}$ GONZÁLEZ MIRAGAYA, S., "Proceso de acceso a la información pública (Ley No 18.381)", en Revista Uruguaya de Derecho Procesal, 3-4/2008, FCU, Montevideo, pp. 339-350.

${ }^{19} \mathrm{Cfr}$., Tribunal de Apelaciones en lo Civil de $5^{\circ}$ Turno, sentencia n ${ }^{\circ} 124 / 2008,14 / 11 / 2008$, Simón -redactor, Presa, Salvo.
} 
Vale anotar que se han previsto mecanismos que han buscado facilitar y flexibilizar la realización de las solicitudes de acceso a la información pública a través de canales digitales. A modo de ejemplo, en el ámbito gubernamental se ha creado el sitio: $<$ http://solicitudesacceso.gub.uy/>, mientras que en el ámbito de la sociedad civil -y de modo similar a lo que sucede en otras países- se puede ubicar el proyecto de CAinfo y DATA Uruguay: <https://quesabes.org/>.

El plazo de que dispone la administración u organismo es de veinte días hábiles, prorrogables -mediando circunstancias excepcionales- por otros veinte días hábiles (art. 15 de la Ley № 18.381 y modificativas, entre otros).

Se puede destacar, también, que en el art. 18 de la Ley $N^{\circ} 18.381$ se ha previsto el "silencio positivo", el cual implica que el organismo requerido sólo podrá negar la expedición de la información solicitada mediante resolución motivada del jerarca que señale su carácter reservado o confidencial, indicando las disposiciones legales en que se funde. Vencido el plazo de veinte días hábiles o vencida la prórroga sin que exista resolución expresa notificada al interesado, éste podrá acceder a la información respectiva, considerándose falta grave la negativa de cualquier funcionario a proveérsela. El proceso judicial procede, por ejemplo, cuando el sujeto obligado se hubiese negado a proporcionar la información o no lo hubiese hecho en el plazo previsto en el mencionado procedimiento administrativo especial.

En definitiva, la regulación uruguaya dispone de una etapa pre-judicial (eventualmente, de tipo administrativo) y una judicial (esto es, el proceso judicial para la tutela del habeas data propio o impropio).

Al mismo tiempo, y como vía independiente, se puede acudir, consultar y/o denunciar ante los organismos de contralor que funcionan en la órbita de la Agencia de Gobierno Electrónico y Sociedad de la Información y del Conocimiento (AGESIC), los incumplimientos a las respectivas normativas. Dichos organismos son la Unidad Reguladora y de Control de Datos Personales (URCDP) y la Unidad de Acceso a la Información Pública (UAIP).

Se trata de una diferencia con otros ordenamientos, como el español, que ha previsto una fase ante el responsable de la base o fichero y otra fase o instancia ante el organismo de control. ${ }^{20}$

${ }^{20}$ Cfr., PÉREZ-LUÑO ROBLEDO, E., El procedimiento de habeas data. El derecho procesal ante las nuevas tecnologías, Dykinson, Madrid, 2017, pp. 160-ss. En la actualidad, los procedimientos en caso de posible vulneración de la normativa de protección de datos que tramitan en España ante la Agencia 


\section{LA DEMANDA, EMPLAZAMIENTO Y AUDIENCIA}

La demanda judicial, debidamente presentada ante los órganos judiciales con competencia en la materia (en el caso de la protección de datos personales, órganos judiciales que entienden en la materia civil y/o contenciosa administrativa, según los casos), da inicio a un proceso de tipo principal, de conocimiento y contencioso.

Se trata de actos de proposición que deben cumplir con los requisitos previstos con carácter general para los escritos de demanda que se encuentran consagrados, básicamente, en el art. 117 del Código General del Proceso. Vale consignar que la demanda puede ser rechazada in limine por ser manifiestamente improcedente. ${ }^{21}$

Con relación al emplazamiento no hay mayores particularidades, más allá de las dificultades prácticas que se pueden eventualmente producir desde el punto de vista del Derecho Internacional Privado en casos de habeas data propio, en los cuales la jurisdicción competente sea la nacional, pero en los que exista un tratamiento remoto, masivo y/o a distancia ( $y$ a nivel internacional) de los datos personales.

La sumariedad del proceso no puede dejar de lado principios y garantías esenciales, que se encuentran por encima de la solución legal, debiéndose practicar eventualmente- el emplazamiento en el extranjero.

Sin perjuicio de lo cual, se deben encontrar mecanismos de cooperación judicial ágiles que faciliten la individualización, localización y notificación de estos sujetos, muchas veces escudados en el anonimato, en la profundidad de las redes, o en la complejidad del flujo transfronterizo de datos. ${ }^{22}$

Resultaría muy interesante contar con una disposición como la prevista en el art. 8 de la Ley de amparo uruguaya (Ley $N^{\circ} 16.011$ ) que establece que la "circunstancia de no conocerse al responsable del acto, hecho u omisión impugnados", no obstará a la

Española de Protección de Datos se encuentran consagrados en los arts. 64 y ss. de la Ley Orgánica $3 / 2018$, de 5 de diciembre, de Protección de Datos Personales y garantía de los derechos digitales.

${ }^{21}$ En la jurisprudencia uruguaya se detectan casos de rechazo liminar de demandas judiciales de habeas data. Se trata de una facultad de los tribunales que puede y debe ser ejercida con cautela, de modo de no atentar contra el acceso a la justicia, el principio pro actione, la tutela jurisdiccional efectiva, etc. A modo de ejemplo: Tribunal de Apelaciones en lo Civil de $3^{\circ}$ Turno, sentencia $n^{\circ} 77 / 2017$, de 11/08/2017 (Kelland -redactor-, Alonso, Opertti); Tribunal de Apelaciones en lo Civil de $6^{\circ}$ Turno, sentencia $n^{\circ}$ 161/2012, de 20/06/2012 (Hounie -redactor-, Klett, Martínez).

${ }^{22}$ Con relación al flujo transfronterizo de datos, apréciese -a modo de ejemplo- la problematización del tema en el Reglamento de la Unión Europea 2016/679, del Parlamento Europeo y del Consejo, de 27 de abril de 2016, "relativo a la protección de las personas físicas en lo que respecta al tratamiento de datos personales y a la libre circulación de estos datos y por el que se deroga la Directiva 95/46/CE (Reglamento general de protección de datos)", considerandos $n^{\circ} 5,101,116$, entre otros. 
presentación de la demanda, en cuyo caso el Juez se limitará a la eventual adopción de las medidas provisorias. ${ }^{23}$

Ni la normativa de protección de datos, ni la de acceso a la información pública, consagran una regla similar. Por el contrario, requieren de la identificación concreta de la autoridad o el particular que debe cumplir, según el caso, con lo señalado en el correspondiente pronunciamiento judicial (art. 43 de la Ley $\mathrm{N}^{\circ} 18.331$ y modificativas, art. 28 de la Ley $N^{\circ} 18.381$ y modificativas). La identificación concreta del demandado puede ser muy dificultosa, en mérito a lo ya señalado, en casos de habeas data propio.

En materia de habeas data impropio, en tanto los sujetos demandados son organismos públicos nacionales, el emplazamiento siempre será en el país.

No obstante, sería interesante reflexionar acerca del acceso a la información que se encuentra en manos de organismos internacionales (de temática muy diversa: desde lo ambiental, hasta lo relacionado con el mundo del trabajo, pasando por la temática financiera-monetaria, hasta las cuestiones bélicas), y si existen mecanismos adecuados que permitan -más allá de las políticas de transparencia activa de dichos organismossu conocimiento.

Finalmente, resta señalar que, en virtud de lo dispuesto en el art. 41 de la Ley $\mathrm{N}^{\circ}$ 18.331 y en el art. 26 de la Ley $N^{\circ} 18.381$, el emplazamiento se realizará conjuntamente con la convocatoria a audiencia. La audiencia, será la oportunidad en la que el demandado podrá adoptar distintas actitudes. Todo en el breve, e inconveniente (a mi juicio), plazo de tres días contados desde la fecha de presentación de la demanda.

A diferencia de la mayoría de los procesos judiciales en Uruguay, el proceso de habeas data se caracteriza porque la oportunidad procesal de contestar la demanda se tiene en la propia audiencia. Ello genera grandes dificultades para el ejercicio adecuado y pleno del derecho de defensa, así como para el diligenciamiento de ciertas probanzas. La urgencia no se vería desatendida si en lugar de esa regulación se previera un plazo para contestar la demanda por escrito (cuya extensión se podría discutir, pero en todo caso sería un plazo claramente definido), previo a la audiencia.

Entiéndase bien, la audiencia se convocará para una fecha no posterior a los tres días de presentada la demanda y dentro de ese exiguo plazo se tendrá que dictar la providencia del Juez y realizar, con la mayor celeridad posible, el emplazamiento y

\footnotetext{
${ }^{23}$ Expresa Biasco, analizando el proceso de amparo, que: "Se trata de una situación excepcional en que se demanda a un desconocido, sin previo emplazamiento, ni designación de defensor de oficio. (...) Admitida la demanda, el juez sólo se limitará a la adopción de las medidas provisionales, en cuanto se hubieren acreditado los extremos exigidos por el art. $7^{\circ} . .$. . Cfr., BIASCO MARINO, E., El amparo general en el Uruguay, AEU, Montevideo, 1998, p. 196.
} 
notificación al demandado, quien a su vez debe preparar su defensa, para luego, en audiencia, contestar la demanda o presentar las "explicaciones" del caso y diligenciar la prueba.

Con relación a ese punto, se debe agregar que no admitir prueba relevante por dificultades operativas o propias de la estructura sumaria, podría derivar en una vulneración del derecho al debido proceso. Lo anterior determina que en estos procesos -y en general en cualquier proceso jurisdiccional que se precie de tal- se deban instrumentar los mecanismos necesarios para habilitar la producción de toda la prueba relevante y necesaria. Es que, en palabras de Couture: "La ley que haga imposible la prueba es tan inconstitucional como la ley que haga imposible la defensa.". ${ }^{24}$

Piénsese en la eventualidad de que se requieran pruebas complejas, tales como pericias informáticas o prueba por informes de amplio contenido. A modo de ejemplo, los soportes de las bases de datos pueden ser de difícil acceso, incluso para peritos no acostumbrados a su manejo (posiblemente, los más especializados en el manejo de ciertas bases de datos sean los propios técnicos de la parte demandada). En ese sentido Taruffo hace algunos años ya ponía de manifiesto algunas de las dificultades que se pueden derivar del análisis de equipos informáticos u ordenadores como fuentes de prueba: "En realidad, la práctica actual en todo el mundo es usar los registros computarizados como único soporte en muchas transacciones. $Y$ cuando estas transacciones tienen que ser probadas en un proceso judicial pueden plantearse varios problemas: Ios datos pueden estar almacenados en diferentes sitios; es posible emplear distintas bases de datos y sistemas de software; la información relevante puede estar oculta o protegida, etcétera.” Asimismo, señala que: “...el peligro de falsificación, errores y mal uso o abuso se da de forma especialmente frecuente y relevante, siendo su alcance, en alguna medida, todavía desconocido." (énfasis agregado). ${ }^{25}$

Por todo ello es que deben diseñarse espacios propicios para la operatividad y la efectividad de las garantías procesales básicas, también en lo relativo a la posibilidad de probar. Que luego ese derecho a probar no sea utilizado en cada ocasión, no significa que el mismo no sea necesario.

\footnotetext{
${ }^{24}$ COUTURE, E. J., Estudios de Derecho Procesal Civil, Tomo I, $4^{\text {a }}$ edición, Depalma, Buenos Aires, 2003, p. 48.

${ }^{25}$ TARUFFO, M., La prueba, Marcial Pons, Madrid, 2008, p. 86. Sobre la proliferación de la prueba pericial informática o tecnológica, véase, entre otros: BENNASAR, A. J., La validez del documento electrónico y su eficacia en sede procesal, Lex Nova, Valladolid, 2010, pp. 194-200.
} 


\section{iii) SENTENCIA, COSA JUZGADA Y EJECUCIÓN}

La decisión judicial definitiva en el proceso de habeas data debe estar fundada en un estándar de prueba plena o de certeza procesal respecto de las proposiciones acerca de los hechos que han sido planteadas en el caso concreto, salvo que expresamente se hubiese previsto a nivel de las normas procesales un estándar diferente o la flexibilización de la certeza procesal positiva como requisito para la condena. Ello sin perjuicio de la regulación que en cada caso se prevea en materia de carga de la prueba.

En el caso de la sentencia definitiva de los procesos de protección de datos personales y de acceso a la información pública en Uruguay, la misma se debe dictar en la propia audiencia o, a más tardar, dentro de las veinticuatro horas de su celebración (art. 41 de la Ley $N^{\circ} 18.331$ y art. 26 de la Ley № 18.381). Cabe también agregar que, dada la prórroga prevista para la audiencia (por hasta tres días, en casos excepcionales) el dictado de esta sentencia puede no darse en la audiencia inicial, sino que en su prórroga, o incluso dentro de las veinticuatro horas siguientes a la celebración de dicha prórroga de audiencia.

La sentencia puede ser recurrida mediante apelación ante los Tribunales de Apelaciones y, eventualmente, casación, ante la Suprema Corte de Justicia. ${ }^{26}$

Finalmente, en cuanto a la cosa juzgada, considero que la sentencia dictada en los procesos en análisis alcanza la cosa juzgada en sentido formal y material, a diferencia de lo que sucede en el amparo. Conforme lo ya señalado, existió una decisión deliberada del legislador uruguayo en cuanto no admitir la revisión en un proceso posterior de lo resuelto en el proceso de habeas data.

Por ende, una vez ejecutoriada la sentencia sobre habeas data, no corresponde que el mismo sujeto plantee un proceso con el mismo objeto, salvo que varíen las circunstancias de hecho sobre la que se falló en una primera oportunidad.

Queda que el condenado cumpla voluntariamente con la sentencia, en los plazos que se disponga en la misma (que no será mayor de quince días -art. 43 de la Ley $\mathrm{N}^{\circ}$ 18.331 y art. 28 de la Ley № 18.381) o, en su defecto, que se acuda a los procesos de

\footnotetext{
${ }^{26}$ Sobre la admisibilidad del recurso de casación en los procesos de protección de datos personales y de acceso a la información pública, citando la posición del autor, de Gaiero Guadagna y de González Miragaya, véase: Suprema Corte de Justicia, sentencia $n^{\circ}$ 802/2018, de 04/06/2018 (Minvielle redactor-, Martínez, Chediak, Hounie, Turell).
} 
ejecución previstos con carácter general -ya que no hay especificidades en el punto- en el Código General del Proceso (arts. 371 y ss.).

\section{IV) A MODO DE CIERRE. LOS “VULNERABLES” TECNOLÓGICOS}

La relevancia asignada en el Derecho comparado a la temática del habeas data propio e impropio es incuestionable.

La plataforma regulatoria que ofrecen los distintos ordenamientos jurídicos resulta cada vez más vasta, incluyendo disposiciones constitucionales ${ }^{27}$, legales, reglamentarias, además de instrumentos internacionales ${ }^{28}$ (y de lo que proviene, también, de la propia regulación contractual o del soft law).

La normativa se encuentra en constante modificación y avance. Las novedades regulatorias asumen un ritmo constante. La actualización es permanente.

Todo ello en parte debido a las exigencias internacionales, a los estándares o parámetros globales que convergen en ciertas pautas mínimas y comunes, para tratar una problemática también global.

En cualquier caso, lo que entiendo debe quedar claro y, por cierto, perfeccionarse y afianzarse, siempre con una visión crítica, es la necesidad de que los mecanismos de tutela jurisdiccional en cuestiones de habeas data sean efectivos (tanto en la etapa del conocimiento procesal como en la de ejecución), simples y adaptados a las particularidades de objeto del proceso (como ser, en ciertos casos, la urgencia). ${ }^{29}$

Considero que el punto también se vincula con la tutela de las personas vulnerables (vulnerables tecnológicos que somos prácticamente todos); y con ciertos fenómenos sociológicos, económicos, culturales, que hacen a la diferenciación existente

${ }^{27}$ Como referencia meramente ilustrativa a las Constituciones latinoamericanas (no exhaustiva): Constitución de la Nación (Argentina), art. 43; Constitución Política de Bolivia, arts. 130 y 131; Constitución de la República Federativa del Brasil, arts. 5 LXIX, LXXII, LXXVII; Constitución Política de los Estados Unidos Mexicanos (actualizada a 2017), art. 6; Constitución Política de Perú (1993), arts. $2 n^{\circ} 5$ y $6,201 n^{\circ} 3$, 202. Uruguay, en tanto, no tiene referencia constitucional expresa al habeas data.

${ }^{28}$ Instrumentos internacionales que, incluso, se ven trasplantados, de diverso modo, a las legislaciones nacionales. Como un caso algo curioso, Uruguay, por ejemplo, optó por aprobar mediante ley nacional (Ley $\mathrm{N}^{\circ} 19.030$, de 27 de diciembre de 2012), el Convenio $\mathrm{N}^{\circ} 108$ del Consejo de Europa para la protección de las Personas con Respecto al Tratamiento Automatizado de Datos de Carácter Personal de 28 de enero de 1981 adoptado en Estrasburgo y el Protocolo Adicional al Convenio para la Protección de las Personas con Respecto al Tratamiento Automatizado de Datos de Carácter Personal, a las Autoridades de Control y a los Flujos Transfronterizos de Datos adoptado en Estrasburgo, el 8 de noviembre de 2001.

${ }^{29}$ SOBA BRACESCO, I. M., "Declaración a favor de la simplicidad procesal", en Derecho Procesal [blog], <http://ignaciosoba-derechoprocesal.blogspot.com/2019/05/declaracion-favor-de-la-simplicidad.html> (consultado el 09/10/2019). 
entre las llamadas "partes (litigantes) ocasionales" y las "partes (litigantes) habituales" o "institucionales". Se debería continuar reflexionando acerca de la efectividad de los mecanismos procesales de tutela, en los casos de tratamiento masivo, a distancia e internacional, de los datos personales, por parte de partes organizadas a tal fin.

Destaca Taruffo que la organización, a diferencia del litigante ocasional, "...se involucra normalmente en una 'serie' de controversias iguales o al menos similares por el objeto y por el tipo de problemática jurídica". El sujeto individual solo de manera fragmentaria y ocasional recurre al proceso, mientras que el sujeto - organización, ve en el proceso un fenómeno o riesgo habitual, en el ámbito de la actividad institucional que desarrolla. Hay una serie de ventajas estratégicas desde el punto de vista procesal para la parte habitual (basadas en elementos sociológicos, económicos, etc.), que hacen que el análisis costo/beneficio se efectúe en términos diversos que para la parte o litigante ocasional. ${ }^{30}$

En ese sentido, los litigantes ocasionales o individuales, sean o no sujetos vulnerables, también puede que terminen decidiendo no iniciar ningún tipo de proceso jurisdiccional por considerar que se encuentran en situación especialmente desventajosa y que es casi inexistente la posibilidad de dar trámite, con éxito, a su reclamo de habeas data.

${ }^{30}$ Cfr., TARUFFO, M., El proceso civil adversarial en la experiencia americana, Temis, Bogotá, 2008, pp. 77-78. Ya con anterioridad Cappelletti y Garth habían estudiado el problema de los litigantes ocasionales y habituales (citando -al igual que Taruffo- a Galanter), al considerar los obstáculos a superar para el efectivo acceso a la justicia. Véase, para una mejor ilustración, CAPPELLETTI, M.; GARTH, B., El acceso a la justicia. Movimiento mundial para la efectividad de los derechos. Informe general, Colegio de Abogados del Departamento Judicial de La Plata, Buenos Aires, 1983, p. 34. 


\section{BIBLIOGRAFIA CONSULTADA}

ALMEIDA IDIARTE, R., "La tutela procesal del derecho al olvido", en Revista Uruguaya de Derecho Procesal, 2/2017, FCU, Montevideo, pp. 223-231.

BARRIOS DE ÁNGELIS, D., Teoría del proceso, BdeF, Montevideo, 2005.

- El proceso civil, Idea, Montevideo, 1989.

BENNASAR, A. J., La validez del documento electrónico y su eficacia en sede procesal, Lex Nova, Valladolid, 2010, pp. 194-200.

BIASCO MARINO, E., El amparo general en el Uruguay, AEU, Montevideo, 1998.

BUENO DE MATA, F., Prueba electrónica y proceso 2.0., Tirant lo Blanch, Valencia, 2014.

CAPPELLETTI, M.; GARTH, B., El acceso a la justicia. Movimiento mundial para la efectividad de los derechos. Informe general, Colegio de Abogados del

Departamento Judicial de La Plata, Buenos Aires, 1983.

COUTURE, E. J., Estudios de Derecho Procesal Civil, Tomo I, 4ae edición, Depalma, Buenos Aires, 2003.

- Proyecto de Código de Procedimiento Civil, Montevideo, 1945.

GAIERO GUADAGNA, B. J., SOBA BRACESCO, I.M., "Constitucionalidad de la Ley Nro. 18.381 de acceso a la información pública (Comentario de jurisprudencia)", en Revista de Legislación Uruguaya, Sistematizada y Analizada, Año IV, № 6, La Ley Uruguay, Montevideo, 2013, pp. 879-885.

- "La regulación de la Central de Riesgos Crediticios en la Ley 18.812. Análisis de su vinculación con el régimen general aplicable a la protección de datos personales", en Revista de Legislación Uruguaya. Sistematizada y Analizada, Año III, № 6, La Ley Uruguay, Montevideo, 2012, pp. 19-27.

- "Comentarios de Legislación acerca del Habeas data propio e impropio en el Uruguay (Leyes Nro. 18.331 y 18.381 y Ley de Presupuesto Nacional Nro. 18.719)", en Revista de Legislación Uruguaya. Sistematizada y Analizada, Año II, № 3, La Ley Uruguay, Montevideo, 2011, pp. 5-32.

- "Aplicación supletoria del Código General del Proceso en el proceso de habeas data", en XVas. Jornadas Nacionales de Derecho Procesal (mayo 2011 - Mercedes), FCU, Montevideo, 2011, pp. 381-388.

- "El proceso de habeas data: análisis de su objeto y estructura", en Revista de Derecho y Tribunales, № 13, AMF, Montevideo, 2010, pp. 81-101.

- "El proceso de hábeas data en el Uruguay (protección de datos personales y acceso a la información pública)", en Anuario de Derecho Constitucional Latinoamericano, Konrad Adenauer Stiftung, Montevideo, 2010, pp. 325-349.

- La regulación procesal del habeas data, BdeF, Buenos Aires, 2010. 
GONZÁLEZ MIRAGAYA, S., "Proceso de acceso a la información pública (Ley No 18.381)", en Revista Uruguaya de Derecho Procesal, 3-4/2008, FCU, Montevideo, pp. 339-350.

- "Naturaleza jurídica del proceso de hábeas data, sus consecuencias y otros aspectos procesales", en Revista Uruguaya de Derecho Procesal № 1/2008, FCU, Montevideo, pp. 59-72.

GOZAíNI, O., Habeas data, Rubinzal Culzoni, Santa Fe, 2001.

MASCIOTRA, M., El habeas data. La garantía polifuncional, Platense, La Plata, 2003.

PÉREZ-LUÑO ROBLEDO, E., El procedimiento de habeas data. El derecho procesal ante las nuevas tecnologías, Dykinson, Madrid, 2017.

PINTO PALACIOS, F., PUJOL CAPILLA, P., La prueba en la era digital, La Ley Wolters Kluwer, Madrid, 2017.

SOBA BRACESCO, I. M., "Declaración a favor de la simplicidad procesal", en Derecho Procesal [blog], <http://ignaciosobaderechoprocesal.blogspot.com/2019/05/declaracion-favor-de-la-simplicidad.html> (consultado el 09/10/2019).

TARUFFO M., La prueba, Marcial Pons, Madrid, 2008.

- El proceso civil adversarial en la experiencia americana, Temis, Bogotá, 2008.

- "Racionalidad y crisis de la ley procesal", en Doxa. Cuadernos de Filosofía del Derecho, № 22, 1999, <http://www.cervantesvirtual.com/obra/racionalidad-y-crisis-dela-ley-procesal/ > (consultado el 09/10/2019), pp. 311-312.

THOMASSET LOUREIRO, M.L., Transparencia y Democracia. El acceso a la información pública, FCU, Montevideo, 2016. 